\title{
UM ESTUDO SOBRE O PERFIL TECNOPEDAGÓGICO DO PROFESSOR DE LÍNGUAS DO SÉCULO XXI: VOCÊ É TECNOFÓBICO, TECNOFÍLICO OU TECNOSTÊNICO?
}

\section{A STUDY ON THE TECHNOPEDAGOGICAL PROFILE OF THE 21ST-CENTURY LANGUAGE TEACHER: ARE YOU TECHNOPHOBIC, TECHNOPHILIC OR TECHNOSTENIC?}

\author{
Fábio Rodrigo Bezerra de Lima* \\ Áurea Suely Zavam**
}

\begin{abstract}
RESUMO: Diversas nomenclaturas provêm de pesquisas que relacionam as gerações e as tecnologias digitais: geração digital, geração X, Y, residentes digitais, entre outras (WHITE, 2008; TAPSCOTT, 2010; PRENSKY, 2012). No entanto, embora já haja pesquisas sobre a relação que os professores mantêm com as tecnologias digitais em sua vida pessoal e profissional (SAITO, 2011; FERONATO, 2012; SELBER, 2014; REIFF, 2019), se faz necessário uma investigação de um tema em constante transformação. Para tanto, neste trabalho é feita uma contextualização histórica de dois perfis, denominados "tecnopedagógicos", conhecidos como tecnofóbicos e tecnofílicos (DEMO, 2009; RONIT, 2011; LAM, 2015) para em seguida ser proposto um terceiro termo chamado de "tecnostênico" com o intuito de abranger um terceiro perfil de usuários e investigar se essa relação influencia ou é influenciada pela prática docente. A partir de dados coletados com professores do Instituto Federal do Ceará, e de análise qualitativa desses resultados, se identificou a percepção em relação à incorporação tecnológica, concluindo que há defluência no que tange os três perfis e no que podem acarretar na prática docente, bem como o que pode ser feito para uma mudança mais ampla no ato laboral docente.
\end{abstract}

Palavras-chave: Tecnologias digitais. Formação de professores. Perfil do professor.

\begin{abstract}
Several nomenclatures come from research that relates generations and digital technologies: digital generation, generation X, Y, digital residents, among others (WHITE, 2008; TAPSCOTT, 2010; PRENSKY, 2012). However, although there is already research on the relationship that teachers have with digital technologies in their personal and professional lives (SAITO, 2011; FERONATO, 2012; SELBER, 2014; REIFF, 2019), it is necessary to investigate a constantly changing theme. Therefore, in this work, a historical contextualization of two profiles, called "technopedagogicals", known as technophobic and technophilic (DEMO, 2009; RONIT, 2011; LAM, 2015) is made, and then a third term called "technostenic" is proposed. in order to cover a third user profile and investigate whether this relationship influences or is influenced by teaching practice. Based on data collected from professors at the Federal Institute of Ceará, and qualitative analysis of these results, the perception regarding technological incorporation was identified, concluding that there is an influence in terms of the three profiles and in what they can cause in teaching practice, as well as what can be done for a wider change in the teaching work.
\end{abstract}

Keywords: Digital technologies. Teacher training. Teacher profile.

\footnotetext{
* Professor no Instituto Federal do Ceará. Participa ainda de dois grupos de pesquisa, LABDATE, com ênfase em educação e tecnologia e o GEECALL, com foco em pesquisas em CALL. T. Doutorando Programa de Pós-graduação em Linguística (PPGLin) da Universidade Federal do Ceará. E-mail: rodrigo_bezerra1@yahoo.com.br

** Graduada em Letras (Licenciatura Português-Espanhol) pela Universidade do Estado do Rio de Janeiro (1979), especialista em Leitura e Escrita (1994), Mestre (1998), Doutora (2009) em Linguística pela Universidade Federal do Ceará (UFC) e Pós-doutora em Estudos Linguísticos (2016) pela Universidade Federal de Minas Gerais (UFMG). Professora da Unidade de Prática de Ensino do Departamento de Letras Vernáculas, do Programa de Pós-graduação em Linguística (PPGL) e do Mestrado Profissional em Letras (ProfLetras) da UFC. Coordena o grupo de pesquisa Tradice (UFC) e participa dos grupos de pesquisa Protexto (UFC) e Praetece (Uece). Coordenadora regional, no Ceará, do Projeto Nacional para a História do Português Brasileiro (PHPB). Tem experiência na área de Linguística Aplicada, em interface com Linguística Histórica e Linguística de Texto, atuando principalmente nos seguintes temas: tradições discursivas; análise de gêneros; leitura, escrita, análise linguística e ensino; formação de professores. Atualmente é coordenadora do ProfLetras-UFC. E-mail: aurea.ufc@gmail.com
} 


\section{Introdução}

Durante as últimas duas décadas muito se pesquisou (e ainda se pesquisa) sobre o perfil dos alunos do século XXI. Em decorrência desses estudos, diversos rótulos e nomenclaturas surgiram numa tentativa de designar esses sujeitos: nativos digitais, residentes digitais, imigrantes digitais, geração digital, geração $\mathrm{Y}$, entre outros (retomaremos mais à frente a definição desses termos). Não se fala, contudo, na mesma proporção, na relação que o professor tem com as tecnologias digitais ${ }^{1}$ no âmbito social, cultural ou profissional. Sem dúvida, há inúmeros trabalhos sobre técnicas e metodologias apoiadas no uso das tecnologias (HUNG, 2006; KRUMSVIK , 2011; PUENTEDURRA, 2011; COSCARELLI, 2016), mas percebe-se que o perfil do ser humano, professor especificamente, e sua relação e história de vida com as tecnologias de informação e comunicação (TIC) é imperativamente relegado. Muitas vezes, a impressão que se tem é que a formação inicial ou continuada seria o primeiro contato do professor com as tecnologias. Vale ressaltar que há professor que já pode ser um nativo digital, isto é, ser jovem e ter nascido, portanto, nessa sociedade digital em que vivemos. Por outro lado, devemos lembrar, em polo oposto, um professor que só teve contato com as TIC na fase adulta e muito depois de anos de sua experiência em sala de aula.

Identificar e compreender os perfis dos docentes de línguas é uma contribuição importante, tanto para áreas da educação quanto para a da linguística aplicada, pois, além de classificar, possibilita uma possível intervenção de pesquisadores, que poderão planejar a ação (ou mesmo investigação) já dispondo dessa informação específica, sem falar que conhecer o perfil docente nos diz sobre o seu agir e consequentemente sobre a concepção de ensino desse profissional.

A pergunta que gerou este artigo surgiu de um olhar crítico sobre a formação de professores de línguas oriundos da graduação a distância (e do presencial em contraste) e sobre o uso que esses profissionais fazem das tecnologias digitais. Alguns questionamentos tomaram forma à época: qual a percepção que os professores de línguas tinham de sua incorporação tecnológica e se isso havia influência em seu trabalho.

Partindo desses questionamentos, nos interessa neste presente artigo chegar a uma descrição do perfil tecnológico, ou como denominamos "perfil tecnológicopedagógico", ou somente "tecnopedagógico". O que estamos concebendo como perfil tecnopedagógico diz respeito a relação que o professor desenvolve com as TIC e consequentemente com o espaço/uso que as TIC têm na sua prática docente. $\mathrm{Na}$ literatura já são apontados alguns perfis e sobre eles teceremos alguns comentários na seção seguinte. A nossa contribuição caminha, pois, na direção de apontar um outro perfil, até então não descrito. Para atingirmos esse objetivo, vamos incialmente fazer uma revisão de literatura sobre os perfis dos alunos e dos professores em relação ao uso que fazem das TIC. A partir daí, pretendemos responder algumas questões de pesquisa baseadas nos dados coletados. i) qual o nível de integração tecnopedagógica baseandose nos dados coletados de professores de línguas do IFCE (Instituto Federal do Ceará)? ii) Há diferenças que podem ser percebidas na atuação do docente considerando os diferentes perfis? iii) qual a percepção que os professores de línguas do IFCE têm da

\footnotetext{
1 Segundo Ribeiro (2000, online): Tecnologia digital é um conjunto de tecnologias que permite, principalmente, a transformação de qualquer linguagem ou dado em números, isto é, em zeros e uns $(0$ e 1). Uma imagem, um som, um texto, ou a convergência de todos eles, que aparecem para nós na forma final da tela de um dispositivo digital na linguagem que conhecemos (imagem fixa ou em movimento, som, texto verbal), são traduzidos em números, que são lidos por dispositivos variados.
} 
sua própria integração tecnopedagógica e quais suas consequências? O estudo nos levou a defender um novo perfil e a entender como os professores percebem a sua própria prática. Mas, antes de apresentá-lo, vamos percorrer o caminho que nos levou a tal proposição, com o desenvolvimento de um breve estado da arte da classificação dos aprendizes, e posteriormente dos perfis que nomeiam o trabalho.

\section{A era digital: os novos aprendizes}

Retomamos inicialmente alguns perfis e termos já largamente descritos e identificados na literatura relacionados aos aprendizes (crianças ou jovens) do século XXI, e também a professores, em alguns casos. Iniciamos com o que se chama de letrados digitais. Esse termo é empregado para se referir àqueles que leem e escrevem com desenvoltura nos ambientes virtuais e que detêm o conhecimento de diversas tecnologias digitais no dia a dia e as transformam de acordo com suas necessidades, inclusive profissionais. No caso de professores, refere-se aos que sabem e usam as tecnologias que lhes são possíveis no ambiente escolar ou fora dele (mas que tenha como objetivo uma melhora no aprendizado ou em uma melhor construção didática). Não podemos confundir o termo letrado digital com alfabetizado digital, pois, como bem sabemos, um indivíduo alfabetizado, ainda que digital, não é necessariamente um indivíduo letrado. Buzato (2006, p. 6), quando se refere a um professor letrado digital, considera:

[aqueles] que saibam avaliar a credibilidade, determinar a aplicabilidade e a relevância dos conteúdos e das ferramentas digitais, mas também queremos que isso sirva para intervirem crítica e criativamente naqueles códigos e formatos que ainda contam para a sua inclusão social, acadêmica, profissional, etc. Desejamos que sejam capazes de tolerar a vagueza, o conflito, os múltiplos pontos de vista, expressos através de múltiplos códigos, vozes e percursos na WWW, mas também queremos que isso sirva para valorizar a diversidade e questionar as desigualdades que existem na escola.

Buzato (2006) se refere a todos os tipos de docentes considerados ideais da nova era e questiona as formações inadequadas nas universidades e nas formações continuadas, alertando que é imprescindível que esse profissional "efetivamente integre o computador à sua prática profissional e a transforme para melhor inseri-la no contexto sócio-histórico presente" (p.11). Lima e Araújo (2010, p.249), por sua vez, chamam atenção para a autonomia desse novo sujeito letrado:

Exige-se, do sujeito letrado, autonomia em relação as suas atitudes enquanto responsáveis pelo seu sucesso na construção do conhecimento, tanto individualmente, como de maneira colaborativa. Para isso, o cidadão letrado necessita se relacionar bem com o ritmo acelerado do processo de ensino-aprendizagem ao passo que precisa ser sensato ao compartilhar informações e ao ampliar a dimensão dos significantes de que fará uso.

Um professor formado na modalidade a distância, a princípio, já preencheria os atributos a que se reportam as palavras de Buzato (2006) e de Lima e Araújo (2010), pois, em seu processo de formação (graduação), faria uso quase que exclusivamente da 
tecnologia digital, e por ter essa formação o esperado é que leve para a sua prática pedagógica o uso dessa tecnologia. Mas será que essa expectativa corresponde à práxis? Vamos, então, considerar outros aspectos.

De acordo com o que postulam Buzato (2006) e Lima e Araújo (2010), um professor letrado digital deveria saber se utilizar de diferentes formas de tecnologias que já existem no dia a dia, e, caso necessário, adaptá-las de modo a atender seus propósitos. Mas nem sempre o esperado corresponde ao que é encontrado. Dominar a tecnologia e fazer uso dela para a prática pedagógica ainda é um desafio para muitos professores, formados ou não na modalidade a distância. Cerutti e Giraffa $(2015$, p. 6) salientam essa problemática docente ao afirmarem que "O desafio atualmente se concentra na questão da transposição didática: como fazer com que nativos digitais ao se tornarem professores façam uso pedagógico dos recursos que utilizam para seu cotidiano".

Tapscott (2010) e Prensky (2012) chamam nativos digitais, NET generation ou Millenials, aqueles que já dominam as tecnologias digitais desde a infância, pois já nasceram em um mundo que produz e cria cibercultura. Os letramentos dominados pelo professor nativo digital, teoricamente, facilitariam a prática docente e a transposição didática. Por outro lado, aquele, nascido há mais tempo, seria um imigrante digital, logo teria mais dificuldade de aprendizagem e manuseamento das TIC. Ser imigrante digital, ou mesmo nativo digital, traria implicações para o professor em sua atuação pedagógica?

É oportuno lembrar que essa terminologia (nativo digital / imigrante digital) tem sido questionada, ao serem considerados fatores como posição socioeconômica, geográfica e nível educacional. Fala-se atualmente em residentes digitais e visitantes digitais (WHITE, 2008; WHITE; LE CORNU, 2011), conceitos que abrangem aspectos mais gerais, independentemente de lugar ou idade, por exemplo. ${ }^{2} \mathrm{O}$ quadro abaixo apresenta essas e ainda outras nomenclaturas relacionadas aos tipos de aprendizes com os quais os professores convivem na sala de aula.

Quadro 1 - Conceitos para aprendizes da era digital. (Elaborado pelos autores)

\begin{tabular}{|l|l|}
\hline Letrados digitais & $\begin{array}{l}\text { Pessoas que leem e escrevem bem nos ambientes virtuais diversos, e utilizam as } \\
\text { TIC no dia a dia adaptando-as as suas necessidades. }\end{array}$ \\
\hline Nativos digitais & $\begin{array}{l}\text { Aqueles que já nasceram rodeados por tecnologias digitais diversas e usam-nas } \\
\text { naturalmente nas diversas esferas sociais. }\end{array}$ \\
\hline Residentes digitais & $\begin{array}{l}\text { Outra nomenclatura similar a dos nativos digitais, contudo abrange aspectos } \\
\text { mais gerais, que relevam além do nascimento, outras características como as } \\
\text { geográficas e socioeconômicas. }\end{array}$ \\
\hline Imigrantes digitais & $\begin{array}{l}\text { São as pessoas que não nasceram com o uso de tecnologias digitais e redes } \\
\text { sociais, e que precisam ou desejam "migrar" para esse novo mundo. }\end{array}$ \\
\hline Millenials & $\begin{array}{l}\text { Outra nomenclatura criada pelo historiador e economista norte-americano Niel } \\
\text { Hoew, usada para a chamada geração Y. }\end{array}$ \\
\hline Geração Y & $\begin{array}{l}\text { Pessoas nascidas entre os anos } 80 \text { e o início dos anos 90 e que verdadeiramente } \\
\text { nasceram no início do "novo mundo tecnológico". }\end{array}$ \\
\hline Geração Z & $\begin{array}{l}\text { São os nascidos da metade dos anos 90 aos dias atuais e que cresceram com os } \\
\text { mais variados artefatos tecnológicos, com a web 2.0, as redes sociais e os } \\
\text { smartphones potentes. }\end{array}$ \\
\hline
\end{tabular}

Fonte: dados da revisão bibliográfica.

No quadro acima há uma breve descrição da nomenclatura atribuída a cada tipo de aprendiz. Nota-se que algumas delas (cf., por exemplo, letrados digitais) correspondem às mesmas características de outras (cf., por exemplo, nativos digitais).

\footnotetext{
${ }^{2}$ Para uma crítica mais pontual dessas classificações, recomendamos os trabalhos recentes (2019-2020) da pesquisadora Ana Elisa Ribeiro (CEFET-MG).
} 
Assim, podemos considerar tratar-se de uma mera questão terminológica de autor para autor. Muitos dos teóricos que abordam essa questão da aprendizagem no século XXI não vêm da linguística aplicada, da educação ou de áreas afins, portanto os trabalhos que buscam relacionar as características desses aprendizes a um contexto formal de aprendizagem na educação formal só vieram a posteriori e ainda assim constata-se uma lacuna que corresponderia à figura do professor nesse contexto, sobre a qual nos debruçaremos na próxima seção.

\subsection{A inserção da figura docente na Era Digital}

Tomando quaisquer das nomenclaturas adotadas, podemos questionar se os professores de hoje se percebem como nativos digitais (ou residentes digitais), e se isso facilitaria, ou não, seu aprendizado e seu manejo das tecnologias digitais e consequentemente a transposição didática ao usá-las. Em caso de dificuldade, como resolver esse problema de transpor conteúdos para residentes digitais? Acreditamos que sendo preparados para aprender e incorporar diferentes recursos tecnológicos em sua prática desde o início de sua formação para o magistério. E aí nos indagamos: as universidades brasileiras (de cursos presenciais ou a distância) preparam os professores de línguas para serem letrados digitais? Esse é um questionamento válido e sua resposta perpassa os projetos políticos pedagógicos (PPP) dos cursos, as disciplinas, os estágios e outras questões da graduação em licenciatura.

Defendemos veementemente a importância de o professor conhecer e utilizar a tecnologia na escola e em várias atividades dessa sociedade cada vez mais enraizada e produtora de cibercultura. Se as crianças e jovens já passam grande parte de seu tempo na web, qual o papel da escola e do professor senão fazer parte desse meio, e usá-lo a seu favor? Gallardo (2010, p.267) questiona o conservadorismo da instituição e dos próprios sujeitos que ainda não se adaptaram aos novos tempos:

O ensino tradicional dessa língua parece não se encaixar com a "mentalidade digital" de grande parte dos aprendizes, que fora da escola têm acesso fácil a jogos virtuais e a Tecnologias de Informação e Comunicação (TICs). Há, no entanto, resistência a mudanças, pois elas significam a extinção de práticas enraizadas na cultura escolar brasileira em troca de novas práticas voltadas para uma nova mentalidade no campo da educação.

Araújo (2007, p.81) entende também que a escola deve ser esse espaço de acesso tecnológico ao conceber "a escola como um lugar propício em que se pode forjar um novo 'intelectual' letrado digitalmente que poderá se inserir "criticamente" em uma sociedade que exige práticas múltiplas de letramento, inclusive digitais." $\mathrm{O}$ termo 'criticamente' nos remete a outro letramento: o crítico. Esse letramento, seja na perspectiva de uma pedagogia crítica freiriana (1970) ou nos estudos de Green (1998), é também importante para professores e alunos, de todas as áreas e níveis, que devem estar inseridos na web, já que o mundo virtual, mais do que qualquer outro, exige um nível de criticidade para, entre outras ações, filtrar informações, reconhecer algum perigo virtual e usar a as ferramentas disponíveis com maior competência.

Coura-Sobrinho e Santos (2010), em um estudo com professores de inglês de cursos livres, de escolas públicas e particulares, sobre a capacidade, a frequência e o uso de tecnologias em suas salas de aula, perceberam que, embora os professores tenham consciência de que as TIC e o uso da web enriqueçam as suas aulas e possam contextualizar o uso de idioma de forma mais real e dinâmica, ainda falta uma formação continuada e um maior aprimoramento profissional, bem como uma estrutura mais qualificada das instituições - melhor nos cursos livres, refletindo no resultado final que possibilitaria mais opções para os docentes. Este é mais um estudo em que não se 
pesquisou o papel do professor formado na modalidade a distância, ainda que confirme que o professor de idiomas moderno deve ser um letrado digital, pois faz parte das atribuições desse novo docente enfrentar "novas demandas na busca da adequação a um determinado perfil do profissional em educação no século 21" (COURA-SOBRINHO; SANTOS, 2010, p.64). Vemos, então, que desse professor, independentemente de ser (ou não) considerado letrado digital, espera-se uma atuação que o qualifique para trabalhar no contexto de tecnologias digitais.

Ainda sobre a questão do Letramento digital e a figura do professor, tem-se visto uma nova corrente, gerada a partir dos estudos de Selber (2014) que classifica o letramento digital em três diferentes fases: LD Funcional, quando pensamos nas Tecnologias como ferramentas e a relação de competência do usuário com seus usos ; LD Crítico quando essas tecnologias são vistas como artefatos culturais e os indivíduos como questionadores dos seus usos; e por fim, LD Retórico, quando as Tecnologias estão representadas como mídias hipertextuais e há uma posição de reflexão crítica em toda as suas possibilidades. No estudo de Nogueira (2014), por exemplo, ela identifica esses letramentos a partir dos saberes de diversos jovens de periferia e de uma professora, à luz do modelo teórico-metodológico de Selber.

Em outro estudo com professores de inglês e a relação de importância que os mesmos davam aos recursos digitais em suas salas de aula, Pereira (2011) se mostrou preocupada, pois percebeu a resistência ao uso ou falta de um letramento digital mais eficaz para os propósitos dos professores. Mesmo que na última década a inserção do docente tenha sido cada vez mais necessária relevante, a falta de uma infraestrutura adequada também não acompanha os anseios da classe.

Um dos maiores documentos brasileiros sobre a realidade do professore de inglês em escola pública, o relatório da British Council (2015), lista os recursos didáticos como primeiro lugar nas dificuldades vivenciadas pelos docentes, com $81 \%$ das queixas dos próprios professores, sendo $43 \%$ desse total relacionado aos recursos tecnológicos. Ou seja, os professores têm anseios em utilizar novos recursos, mas o acesso ainda é muito limitado. É deveras importante tanto prover os recursos necessários como reconhecer os limites e anseios dos professores a partir de seus perfis. Mas como o percebemos? É, pois, sobre o perfil desse professor que passamos a falar.

\subsection{Perfil tecnológico docente}

Vivemos uma era, chamada por alguns especialistas de Tecnocracia (POSTMAN, 1994), em que as novas tecnologias afetam praticamente todas as áreas do conhecimento e da vida, e a sensação de evolucionismo tecnológico, arraigado a um determinismo, nos faz crer que o futuro só será melhor com as novas tecnologias cada vez mais entrelaçadas a nossa rotina pessoal e profissional. Para alguns, essa onda é inevitável por diversos motivos, tais como a concorrência natural inegável do ser humano, a busca incessante de novos compradores, fundada na base de um capitalismo agressivo, e a posição dominante que as empresas tecnológicas encabeçadas pelo vale do silício nos EUA, e nos centros tecnológicos do Japão e na Coreia do Sul, detêm como capitais financeiras no cenário mundial.

Esse mundo é justamente aquele em que as pessoas, especialmente das zonas urbanas, têm que fazer escolhas ("impossível" fugir delas), sobre o uso ou não (exacerbado) das tecnologias digitais: computador, tablet, notebook, e-reader, smartphones, GPS, videogame, smart TV, projetores, aparelhos de som digital, smart watches entre outras. Algumas pessoas organizam a vida em torno dessas tecnologias sempre vendo como aperfeiçoar seu dia e sua ocupação profissional; outras fazem de 
tudo para delas não depender, e preferem não aprender a utilizá-las, a não ser para o que consideram essencial.

Como pontuado por Furtado (2009), ao longo da história, os escritores de ficção científica costumam dividir as sociedades como distópicas (apocalípticas) ou utópicas (paradisíacas) e os governantes e cidadãos, a partir de sua relação com a tecnologia, como tecnofílicos e tecnófobicos. Na literatura e no cinema, o fenômeno muitas vezes é retratado de forma radical, globalizante e até escravizante. Ribeiro (1999) faz ainda uso do termo tecnotopia para demarcar visões redentoras ou amaldiçoadas do efeito inegável da tecnologia nos anos vindouros na sociedade do século XXI. Como exemplificação dos dois modelos de sociedade, podemos citar do lado da distopia o romance sci-fi cyberpunk hard de William Gibson, Neuromancer (1984). Até hoje um marco no gênero por prever e integrar de forma impressionante a tecnologia em uma sociedade ultra-tecno-dependente. Muitos atribuem diversos termos usados nas pesquisas com tecnologia, inclusive ciberespaço (cyberspace) a esse romance. No lado oposto, o da utopia, de forma muito mais rara na literatura, temos o romance "A Mão Esquerda da Escuridão", de 1969, da escritora Ursula K. Le Guin, em que questões de gênero e sexo são colocados em cheque em uma sociedade ideal. Nessa pesquisa, parto da classificação pessoa-tecnologia a partir do trabalho de Demo (2009).

O termo tecnofilia é formado pelo sufixo grego -filia (ou philia), que significa amizade, aproximação, e o radical tecno-, de tecnologia. É empregado no meio da computação (mas cunhado na Sociologia) para designar pessoas que fazem questão de usar tecnologia sempre que podem, e, muitas vezes, de maneira acrítica. São aquelas que "organizam sua vida ao redor de novas tecnologias e acham que sem elas não é possível ter uma vida social de sucesso" (DEMO, 2009). Em um sentido mais amplo, Tecnofilia está relacionada a uma aceitação quanto a adoção de tecnologia em nossas vidas. Essa aceitação pode levar a consequências patológicas relacionadas ao vício e a um comportamento obssessivo Segundo Ronit, (2011), a tecnofilia é percebida a partir de uma adoção positiva e uma normalidade adquiridas a partir da experiência no uso de tecnologia. Segundo o mesmo autor, essa postura tecnofílica é um novo modelo societário amplo e que vem redefinindo populações inteiras, em um movimento pósmoderno incessante.

Por sua vez, o termo tecnofobia é formado pelo sufixo grego -fobos (ou phobos), que significa medo, e relacionado ao deus do temor, filho de Ares, com o radical tecno-, de tecnologia. É o oposto de tecnofilia. Refere-se a pessoas que têm um distanciamento extremo do uso das novas tecnologias. Preferem não utilizar, mesmo quando tenham acesso fácil a elas. É completamente avesso e pessimista em relação às novas tecnologias. A tecnofobia (também chamada de cyberofobia) também é considerada uma patologia quando a aversão atinge níveis extremos de um medo exagerado e injustificado do uso impactando em suas relações sociais.

No nível individual com base em sua relação integrativa com a tecnologia, entendemos ser insuficiente uma classificação apenas em dois tipos: tecnofílicos e tecnofóbicos. Assim sugerimos uma nova relação e consequentemente criamos um novo termo classificatório. Um terceiro tipo de pessoa (incluindo o professor) surge em relação ao uso de tecnologias digitais, que chamaremos de tecnostênicos. O termo vem de tecnostenia, que é formado pelo sufixo grego -stenia, que provém da palavra astenia (ou asthéneia) e significa "pouco ou nenhum vigor", "fraqueza", com o radical tecnode tecnologia. Ou seja, tecnostênicos são aqueles que detêm uma fraqueza, uma fragilidade em relação ao uso de tecnologias, mas não uma incapacidade ou rejeição. Quanto à prática de sala de aula, será tecnostênico o professor que revela um nível razoável de letramentos digitais, mas não usa os recursos com frequência e nem está 
"antenado" a novas possibilidades. Também não tem aversão às novas tecnologias e as usa de vez em quando para fugir um pouco da rotina ou quando as usa, repete sempre as mesmas tecnologias.

Em relação ao trabalho docente, em um artigo de 2015, denominado "Technophilia versus Technophobia: technology in the classroom", a autora canadense Yvonne Lam faz essa distinção, usando a mesma classificação de Demo (2009), trazendo os termos para a realidade do professor. $\mathrm{O}$ interesse da autora é compreender se a diferença de gêneros (masculino e feminino) seria um fator característico influenciador para a distinção entre professores tecnofílicos ou tecnofóbicos, além de outras questões que possam interferir no uso das tecnologias pelo docente.

Podemos considerar os termos de forma mais branda do que como descrito nas áreas da computação, psicologia e sociologia. Julgamos, assim, como professores tecnofílicos aqueles que são considerados inovadores, que sempre preferem incluir recursos tecnológicos em seus planejamentos, mesmo que por poucos minutos e mesmo quando a escola não disponibiliza de fartas possibilidades. É alguém que entende razoavelmente bem de tecnologias digitais, e as usa inclusive socialmente. É o que alguns preferem chamar hoje de geek ou technogeek ${ }^{4}$. Já os professores tecnofóbicos são aqueles que raramente incluem algo de tecnologia em seus planejamentos, se atêm aos livros, exposição ou dinâmicas de sala de aula. Não demonstram interesse em aprender a utilizar e, mesmo quando tem algum domínio, acreditam que a tecnologia não faria muita diferença em suas aulas. Por fim, como já pontuado, entendemos que haja um terceiro tipo de professor, aquele que não é nem tecnofílico, nem tecnofóbico, e toma uma posição mais intermediária, "neutra", o considerado tecnostênico.

Os professores podem ser classificados quanto a estes três tipos em relação a habilidade e ao uso de tecnologias digitais na sala de aula. No quadro abaixo, sintetizamos os principais pontos da distinção:

Quadro 02 - Os três perfis de professor quanto ao nível em letramentos digitais.

\begin{tabular}{|l|l|}
\hline $\begin{array}{l}\text { Perfil } \\
\text { professor }\end{array}$ & Habilidade no uso e na incorporação de tecnologias na sala de aula \\
\hline Tecnofílicos & $\begin{array}{l}\text { São professores inovadores que revelam alto nível em letramentos digitais. } \\
\text { Também detêm alto grau de interesse na incorporação de tecnologias digitais em } \\
\text { sua práxis e o fazem constantemente. Estão sempre a par das novidades } \\
\text { tecnológicas. }\end{array}$ \\
\hline Tecnofóbicos & $\begin{array}{l}\text { São professores que rejeitam o uso de tecnologias digitais. São considerados } \\
\text { conservadores e evitam qualquer tipo de incorporação tecnológica. Revelam } \\
\text { baixo nível em letramentos digitais. }\end{array}$ \\
\hline Tecnostênicos & $\begin{array}{l}\text { São professores intermediários quanto a incorporação de tecnologias digitais em } \\
\text { sua práxis. Demonstram um nível razoável em letramentos digitais. Sabem usar as } \\
\text { principais ferramentas e não enfrentam tantos problemas com o uso das } \\
\text { tecnologias. Usam em sala de aula às vezes, só como algum complemento. }\end{array}$ \\
\hline
\end{tabular}

Fonte: dados da pesquisa, 2020

Compreender e classificar o perfil tecnopedagógico do professor é importante, não apenas para uma mera descrição relativa a um determinado posicionamento didático, ou como um esforço intelectual para preencher uma lacuna na ciência. Há um

\footnotetext{
${ }^{3}$ Tecnofilia contra Tecnofobia: tecnologia na sala de aula (tradução nossa)

${ }^{4} \mathrm{Na}$ pesquisa de Maia (2016), ela classifica os professores como geek e não-geek. Embora interessante, entendo que esses termos carregam uma feição que vai além da habilidade ou não em tecnologia, e abrangem o interesse por toda uma cultura nerd. Além disso, como já descrito, uma bipartição apenas é insuficiente.
} 
valor importante nisso, sem dúvida, mas também significa valorizar e estimular cada vez mais professores para agir com eficácia em uma sociedade tecnológica vigente.

Entender esses perfis é imperativo para criar estratégias nas mais diversas áreas de pesquisa e esferas políticas visando estimular e capacitar professores dentro de suas próprias habilidades e limitações. Os professores tecnofílicos precisam compartilhar suas experiências com professores menos familiarizados e usarem de sua expertise para sua prática profissional. Formações continuadas de qualidade precisam atender aos professores tecnofóbicos e tecnostênicos no intuito de vencer algumas barreiras e preconceitos, e assim caminhar em direção ao bem comum que é a qualidade no aprendizado discente. O incentivo a uma postura reflexiva é necessária a partir das licenciaturas, não isentando o professor da sua parcela de responsabilidade com sua própria formação e prática profissional. Não é uma transição rápida, nem fácil, mas necessária. Para McCain \& Jukes (2001), o desenvolvimento tecnológico impõe a mudança, e a mudança traz desconforto.

\section{Desenvolvimento}

\subsection{O desenho metodológico}

Embora tenhamos recorrido a dados numéricos e porcentagens, esta pesquisa tem um caráter qualitativo. Os dados numéricos contribuem para analisar, com foco interpretativo, as informações coletadas, sempre com o suporte dos autores com os quais dialogamos.

\subsection{Procedimentos e participantes}

Os dados foram colhidos a partir de questionário semiestruturado com perguntas abertas e fechadas sobre a relação que o professor tem de sua própria prática com uso de TIC e o reconhecimento de um dos perfis mencionados. No total, 21 (vinte e um) professores de línguas do Instituto Federal do Ceará (IFCE) responderam o questionário disponível na web por meio da ferramenta Google docs. O questionário foi respondido entre os dias 01 e 20 de agosto de 2017.

Os 21 professores participantes da pesquisa foram assim identificados:

a. 12 do sexo feminino e 9 do sexo masculino;

b. 02 com faixa etária entre 20 e 30 anos, 10 com faixa etária entre 31 e 40 anos, e 3 entre 40 e 50 anos de idade;

c. 13 de língua inglesa, 03 de língua espanhola e 05 professores de língua portuguesa.

As perguntas serão apresentadas individualmente, com o devido resultado de cada professor. A partir disso, algumas respostas serão destacadas e serão analisadas à luz do modelo teórico de Selber (2014) e relacionado aos três níveis de letramento digital do professor e também na classificação tecnopedagógica proposta no artigo (tecnofilia, tecnofobia e tecnostenia.)

\section{Discussão e resultados}

As dez perguntas do questionário tinham como foco a percepção do uso das tecnologias pelos professores de línguas. Essa percepção foi confrontada com as definições dos três perfis de professor: tecnofílico, tecnofóbico e tecnostênico. Antes de chegar à própria percepção dos perfis, havia uma série de perguntas sobre a relação 
entre a prática do professor e o uso de tecnologias digitais. Alguns dos dados, gerados pela própria plataforma Google, nos chamaram a atenção e exigiram um olhar mais arguto e dessa forma demandaram uma análise mais detalhada. Para este artigo, utilizaremos especificamente as questões $1,2,4,6,7,8$ e 9 que estão mais próximas às questões de pesquisa anteriormente apontadas. Além disso, cada participante da pesquisa será identificado por sigla ( $\mathrm{P} 1, \mathrm{P} 2, \mathrm{P} 3, \mathrm{P} 4$ etc.) e quando necessário, destacado para a análise de sua resposta. Em relação a questão número 1, Gráfico 1 - Frequencia

1. Com que frequência você costuma integrar tecnologia digital em sua sala de aula?
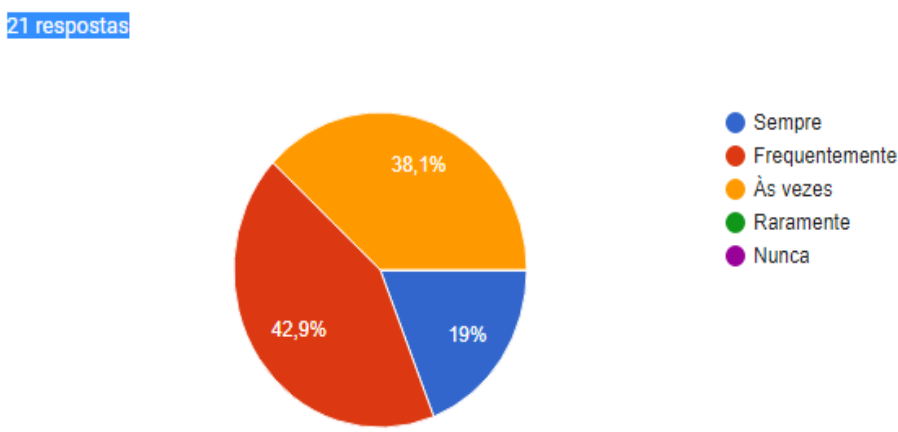

Fonte: dados da pesquisa.

Aqui os professores marcaram em sua maioria "frequentemente" e "às vezes", e para $19 \%$ como "sempre". Contudo, como pergunta inicial, ainda não se sabe muitos detalhes dessa integração. Porém, quando foi questionado sobre o grau de confiança na utilização do equipamento, a opção "às vezes" se sobressaiu. (segue o gráfico abaixo). Entendemos que os professores se sentem confortáveis com certas práticas já internalizadas ou que são mais recorrentes no ensino de línguas (como uso de notebooks, projetores, aparelho de som), mas podem não se desafiarem ou se sentirem seguros com inovações que além dos recursos com quais têm familiaridade.

Gráfico 2 - Inovações tecnológicas

2. Você costuma acompanhar as inovações tecnológicas para uso pedagógico na sua área?

21 respostas
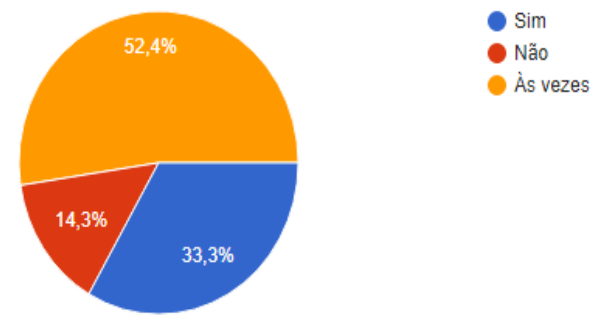

Fonte: dados da pesquisa. 
Gráfico 3 - Frequencia e confiança em utilizar tecnologia

4. Com que frequência você se sente confiante em utilizar qualquer equipamento necessário para uma integração tecnológica em sua aula?

21 respostas

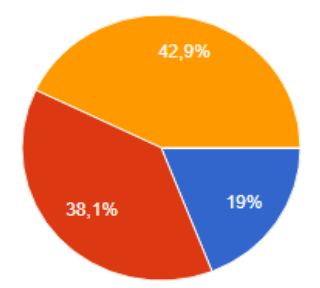

Sempre

- Frequentemente

Às vezes

- Raramente

- Nunca

Fonte: dados da pesquisa.

Já na segunda pergunta (e reforçado com a sua frequência na quarta) é confirmado o fato da maioria dos professores não acompanharem o uso pedagógico de inovações tecnológicas em suas áreas. Estamos questionando apenas 0 acompanhamento dessas inovações e não a integração em si em suas aulas o que seria ainda mais complexo, pois o acesso e a utilização dessas ferramentas ainda dependeriam de vários fatores para o uso pedagógico. Considerando os estudos de Selber (2014), sequer a maioria dos professores se sentiria plenamente confortável com seu próprio nível de letramento digital. Em geral, os professores não marcaram 'raramente' ou 'nunca'. Talvez não estivessem prontos para resolver 'impasses tecnológicos' nos dizeres de Selber.

A pergunta número 8 trazia um quadro explicativo dos três perfis tecnopedagógicos e pedia que o professor respondesse em qual perfil ele mais se encaixaria. O resultado foi o seguinte:

Gráfico 4 - Perfil

8. Baseado nas descrições acima, qual perfil você acha que mais se encaixaria:

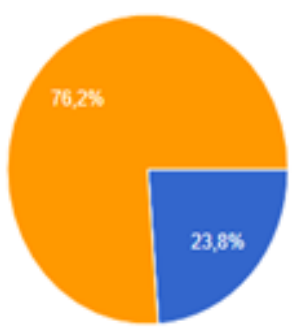

Tecnofilico

Tecnofobico

Tecnosstrico

Fonte: dados da pesquisa.

Nenhum professor se considerou tecnofóbico (rejeita as tecnologias e/ou não sabe utilizá-las) Um baixo número se considerou tecnofílico $(23,8 \%)$ e a grande maioria considerou sua relação mediana, por razões que foram explicitadas acima e que vamos analisar. Não houve nenhuma surpresa quanto ao grande número de professores identificados como tecnostênicos, a partir das respostas anteriores. No estudo de Ronit (2011), os maiores usuários identificados como tecnofílicos não estavam necessariamente relacionados apenas ao nível de letramento digital e a classe socioeconômica (embora sejam fatores importantes), mas ao uso frequente de 
tecnologia como entretenimento e diversão, mesmo que o nível de letramento e socioeconômico não fosse tão alto. Através da experiência positiva, os usuários passam a criar uma relação mais emocional que os ajuda a ultrapassar barreiras e a criar relações mais fortes com as diversas ferramentas, assim é comum encontrar tais perfis em usuários mais engajados nas redes sociais e em jogadores de vídeo game. Embora nesta pesquisa não tenhamos investigado esses perfis relacionados aos professores, é uma hipótese que explicaria um número modesto de professores tecnofílicos.

Na questão número 09 os professores foram quase unânimes em afirmar que o tipo de perfil influência na qualidade como professor $(90,5 \%)$. Subentende-se que ser tecnofílico, ou pelo menos tecnostênico é um perfil importante para uma aula de língua em tempos atuais.

Gráfico 5 - Perfil versus qualidade

9. Você acredita que os perfis tecnopedagógicos mostrados acima

podem influenciar no nível de qualidade nas aulas em sua disciplina?

21 respostas

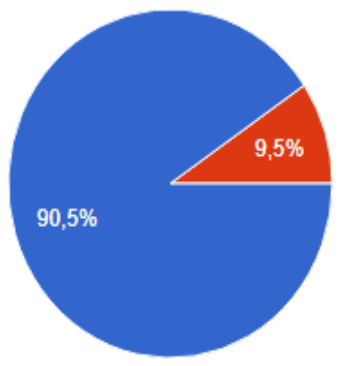

Sim

Não

Fonte: dados da pesquisa.

Vejamos, agora, com mais detalhes, o que os professores dizem utilizar e as dificuldades em utilizar com mais frequências (perguntas 6 e 7). Reproduziremos as perguntas e todas as respostas dadas na plataforma Google docs e logo abaixo, faremos um resumo e a devida análise.

6. Caso você tenha integrado com sucesso e inovação alguma tecnologia em sua aula, poderia fazer uma breve descrição de um exemplo dessa integração?

P1 - Utilizando apps de aprendizado em inglês

P2 -RAE

P3 - Não respondeu

P4 - Utilizo software de legendagem no ensino de LE, o que não é uma prática comum nessa área

P5 - Práticas de leitura multimodal como o site 'mujer palabra' e jogos digitais com com o conteúdo de uma obra literária

P6 - App Kahoot. Edmodo.

P7 - Não respondeu

P6 - Utilizar o aplicativo Duolingo para a terceira nota, aliviando o peso das

demais notas e fazendo o aluno se interessar pela língua estrangeira num esforço diário.

P7 - Uso Plickers, Quizziz, Kahoot, Socrative para revisar conteúdos sempre que possível.

P8 - Tenho usado um aplicativo chamado Plickers. Costumo fazer competições em equipes ao final das etapas. Cadastro questões no site, com seus devidos gabaritos, 
além de cadastrar as equipes. Por meio do aplicativo, vou coletando as questões através de cartões que dou às equipes.

P9 - Ferramenta Kahoot. Jogo interativo de perguntas e respostas que exige conectividade. Foi extremamente eficaz, divertido e estimulante para os alunos. P10 - Citando um exemplo ao trabalhar gêneros textuais, costumo apresentar aos alunos os gêneros as ferramentas da web: blogs, sites, redes sociais, etc. Nesse sentido, a aula consegue integrar tecnologia ao ensino.

P11 - Atividade no kahoot, duolingo etc.

P12 - O uso da palavra tecnologia envolve alguns problemas de significado e de entendimento. Talvez seja limitação minha, mas vejo que o uso do data show, um som é o uso de determinadas tecnologias que não necessariamente são pedagógicas. Eu, por exemplo, uso muitos vídeos em minhas aulas, mas para tratar das formas de comunicação, de produção escrita e oral dos textos, mas tenho dúvidas se essa pesquisa aqui considera esses recursos como tecnologias ou está se referindo somente aos recursos criados para fins pedagógicos.

P13 - Uso do Kahoot e do plickers.

P14 - Kahoot. Site para quizzes bastante interativo.

P15 - Usei Survey Monkey para algumas competições, vídeo-chamada para interação com estrangeiros, apps de vocabulário.

Alguns professores mostram bastante domínio em diversas ferramentas (P4, P7 e P15), mas como a pesquisa se concentrou em questionários, pelo menos a partir apenas dessa questão não podemos a priori classificar os professores em nível de letramento digital crítico, muito menos em retórico. A própria metodologia de Selber (2014) indica ações de longa duração e métodos de coleta de dados como: uso de diários para registros, entrevistas semiestruturadas, confrontamento entre pares e grupos para entender melhor toda a relação que envolveria os letramentos digitais, tal como no trabalho de Nogueira (2014). No entanto, se mostra interessante o questionamento de P12, refletindo sob sua própria prática ao duvidar se a integração real estaria relacionada a tecnologias desenvolvidas para fins pedagógicos ou se o professor de alguma forma as apropriaria ao seu interesse. Seria uma indicação questionadora no segundo nível (LD crítico) do quadro conceitual de Selber.

\footnotetext{
7. Você gostaria de usar a tecnologia nas suas aulas com mais frequência? Caso sim, o que te impede? Caso não, por que não?

P1 - Sim. Verba da instituição, mais tempo em sala de aula

P2 -Sim.

P3 - Sim. Internet as vzs não funciona bem.

P4 - Sim. Suporte tecnológico. Nem todos os alunos têm smartphones e o meu campus é muito limitado no que se relaciona a suporte tecnológico.

P5 - Sim, a concorrência dos laboratórios e a internet ruim do campus.

P6 -Gostaria de usar mais tecnologia. Acabo sempre usando as mesmas

ferramentas, e já que elas funcionam, acabo não me interessando em buscar por outras. Sei que isso é uma falha e pretendo superá-la.

P7 - A falta de estrutura adequada.

P8 - Não tenho problema com o uso de tecnologias.

P9 - Sim. A qualidade da internet no campus me impede.

P10 - Sim. Creio que preciso de maior habilidade para o uso.

P11 Sim. Falta um pouco de conhecimento dessas tecnologias e tempo para pesquisar tais ferramentas.

P12 - Sim mas os fatores que mais me imoedem são acesso à Internet e o domínio das novas tecnologias pois confesso que ainda estou aprendendo a manuseá-las mais efetivamente.
} 
P13 - Sim. Pouco tempo de aula (1h no integrado), problemas técnicos com internet e equipamentos no campus, falta de conhecimento das várias possbilidades de atividades com uso da tecnologia.

P14- Sim. E sempre uso.

P15- Não. Acho que já estou usando o bastante. O perfil do aluno brasileiro ainda é tradicional, ultrapassado, fechado para novidades. Muita inovação é vista como enrolação. Por isso, prefiro dosar bem.

P16- Gostaria muito de usar outras tecnologias, como por exemplo, aplicativos, programas, ferramentas para interação, mas não uso por desconhecimento de quais existem e de sua funcionalidade. Então, é uma limitação operacional e também cognitiva, porque eu preciso dominar os conhecimentos referentes ao uso da língua portuguesa (objetos, conteúdos de ensino na disciplina de Língua Portuguesa) e saber como explorá-los fazendo uso das tecnologias. Dominar esses dois tipos de conhecimento torna o uso de certas tecnologias mais difícil.

P17 - Sim, sempre é bom estar inovando, mas as vezes os campi não estão preparados financeiramente para dar suporte.

P18 - Sim. Atualização sobre o que está disponível.

P19 - Sim. Limitações da instituição (equipamento insuficiente, internet ruim, salas não preparadas para algumas atividades, etc.).

P20 - Sim! Internet oscilante. Falta de computadores, caixas de som...equipamentos em geral. Sim. Sobre as tecnologias que sei usar, muitas vezes a internet no campus é muito ruim, e diria que um terço dos meus alunos não tem acesso a bons equipamentos e internet. E tem as tecs que não sei usar, por exemplo, lousa digital, e tem as que nem sei que existem.

É inegável pelas respostas que os professores reconhecem as limitações cerceadas pela estrutura para desenvolver ainda mais suas habilidades ligadas ao uso tecnológico. Isso já enseja duas reflexões. 1) os professores da pesquisa acreditam que possuem maior potencial e poderiam fazer mais, demonstrando assim uma reflexão sobre a própria atuação. 2) As barreiras limitadoras ( ligadas à estrutura ou à formação) já são bem conhecidas. (atentar para as respostas do P12, P13, P16 e P17). Importante relembrar que os professores são servidores de um instituto federal, com maior e melhor estrutura, comparando com as escolas públicas de ensino básico, e com formação docente, geralmente com nível de mestrado ou doutorado, dessa forma, mais próxima àquela das universidades públicas. As reflexões ecoam no documento da British Council, já apresentado, e na discussão desenvolvida por Pereira (2011).

Fazendo um resumo mais geral das ferramentas utilizadas temos o seguinte desenho:

- Aplicativos de smartphone para aprendizagem de línguas - 9 professores

- Dicionários virtuais - 1 professor

- Uso de redes sociais/sites para trabalhar diversos gêneros - 1 professores

- Softwares de legendagem - 1 professor

- Uso de vídeos e áudios diversos integrado ao conteúdo - 1 professor 
Gráfico 1 : Ferramentas utilizadas pelos professores.

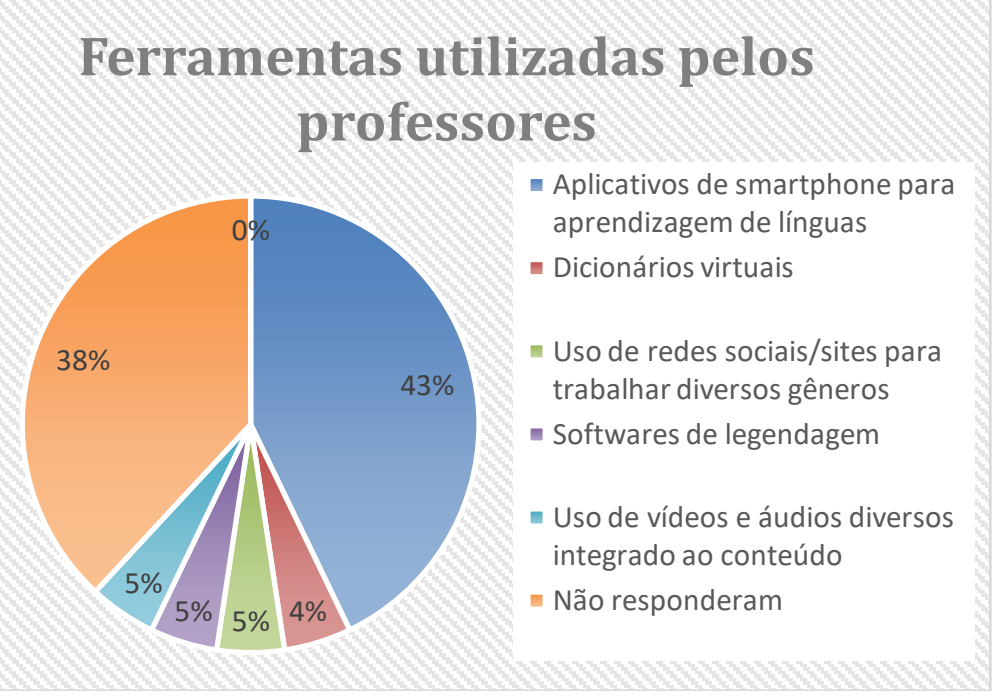

Fonte: dados da pesquisa

Nem todos os professores responderam a questão 6. Tratava-se de uma pergunta subjetiva que pedia a descrição de algum exemplo da incorporação das tecnologias em sua sala de aula. Dos 21, apenas 13 compartilharam suas ferramentas, com um claro domínio dos apps para o aprendizado de línguas, tais como Duolingo ou aplicativos que ensejam competição via quiz, como Kahoot e Picklers. Se consideramos o perfil tecnopedagógico baseados nos exemplos utilizados pelos professores (mesmo que seu uso não seja de forma frequente), percebemos que poucos são os docentes que fazem uma integração mais completa, mesmo que o perfil apontado tenha sido tecnofílico ou tecnostênico. Ou os professores não entenderam o conceito em sua totalidade, ou, o mais provável, outras barreiras o impediram de utilizar essas e outras ferramentas com mais frequência em suas aulas.

Considerando as respostas da pergunta 07 , apenas um professor disse que já usa com a frequência adequada, e em relação as outros 20, 13 relataram problemas ligados às barreiras ditas externas, relacionadas ao equipamento, internet, verba etc. Em geral, fatores além do alcance pedagógico do docente. Em seu estudo de 2000, Lam chega à conclusão similar, destacando muito mais as barreiras encontradas ao perfil tecnopedagógico do professor: "the technophobia of teachers on a gender basis is a mistaken notion. Rather, lack of resources, lack of training and no technical support were found to be the most striking reasons for unwillingness to use technology in class." $(\mathrm{LAM}, 2000)^{5}$.

\section{Conclusão}

Há uma gama de nomenclaturas, muitas vezes, conflitantes, criadas desde a década de 70, que se popularizaram nos estudos de CALL (Computer Assisted Language Learning) ${ }^{6}$ e de letramento digital. Tais nomenclaturas se propõem a estabelecer o nível de aprendizado e de habilidades dos usuários com as tecnologias digitais. No âmbito do fazer científico, é prática comum a de reconhecer padrões e criar

\footnotetext{
${ }^{5}$ A tecnofobia dos professores a partir de uma base de gênero é uma noção equivocada. Ao invés disso, a falta de recursos, falta de treinamento e nenhum suporte técnico foram os motivos mais notáveis para a falta de vontade de usar tecnologia em sala de aula. (tradução nossa)

${ }^{6}$ Aprendizagem de língua assistido ou mediado por computador (Tradução nossa)
} 
tais nomenclaturas para fins didáticos; isso se aplica também a pesquisas em linguística aplicada. Embora muitos dos termos mostrados neste artigo tenham sido criados em outras áreas de pesquisa, como na computação, na sociologia e no marketing, por exemplo, é na educação e na linguística aplicada que muitos dos termos ficaram mais conhecidos devido a uma gama de pesquisas sobre as relações sociais dos profissionais com as tecnologias digitais.

Nosso objetivo aqui foi levantar alguns questionamentos sobre quais seriam os perfis que denominamos tecnopedagógicos para professores e consequentemente se o tipo de perfil faria diferença na atuação pedagógica de cada professor; propusemos inclusive a descrição de um terceiro tipo, não descrito em outras pesquisas sobre o assunto: o tecnostênico. Com base na classificação proposta e tomando como corpus as respostas dadas pelo participantes, fizemos uma breve análise dos resultados obtidos buscando saber um pouco mais sobre a relação dos professores com as tecnologias digitais. É importante salientar que não deixamos de considerar a relação dos aprendizes com as tecnologias digitais e que essa relação é dependente de muitos fatores pregressos, tais como situação socioeconômica, faixa etária, proximidade dos grandes centros urbanos, influência familiar, entre outros. O mesmo raciocínio vale para as categorizações dos professores, e ainda devemos acrescentar aos critérios elencados a formação básica e continuada.

Vale ressaltar também que, quando tratamos de pesquisas sobre tecnologias digitais, sociedade e línguas, é fundamental a compreensão de que são práticas que se transformam frequentemente e que exigem dos pesquisadores uma constante atualização, pois o que é reservado ao ser humano nas suas relações com as "máquinas" é sempre algo a ser descoberto. Por outro lado, não podemos esquecer que a escola, as universidades e os professores, ainda que estejam plenamente inseridos nessa sociedade digital, fazem parte, no nosso caso, de uma realidade que muitas vezes se vê emperrada por uma lentidão que extrapola o fazer docente e que acaba fazendo da busca ao novo, ao atual, uma corrida inalcançável.

Salientamos que mais pesquisas precisam ser desenvolvidas para melhor compreender a consequência da identificação do perfil do professor na sua formação e na sua atuação docente. E assim, baseados em tais pesquisas, pensar nos cursos de licenciaturas a fim de, já no início da graduação, desenhar o perfil que irá melhor preparar o profissional. Ademais, as relações humanas com as tecnologias são dinâmicas e necessitam de constante investigação para o melhor entendimento e para preparar as gerações vindouras, ainda que seja provável que muito do que foi imaginado para os mundos distópicos e utópicos já estejam presentes na nossa era, mas não ainda ao alcance de todos. A propósito, a título de encerramento, retomamos a célebre frase de William Gibson, autor já mencionado, escritor do clássico Neuromancer, que ainda nos anos 80 profetizou "o futuro já chegou, ele só não foi repartido igualmente ainda".

\section{Referências}

ARAÚJO, J. C. Os gêneros digitais e os desafios de alfabetizar letrando. Trab. Ling. Aplic., Campinas, 46(1): 79-92, jan./jun. 2007.

BRITISH COUNCIL. O ensino de inglês na educação pública brasileira: elaborado com exclusividade para o British Council pelo Instituto de Pesquisas Plano CDE. São Paulo, SP: British Council Brasil, 2015. Disponível em:<

https://www.britishcouncil.org.br/sites/default/files/estudo_oensinodoinglesnaeducacao publicabrasileira.pdf $>$. Acesso em 08 de ago. 2018. 
BUZATO, M. E. K. Letramentos digitais e formação de professores. III Congresso Ibero-Americano EducaRede: Educação, Internet e Oportunidades. Memorial da América Latina, São Paulo, BRASIL, maio 2006.

CERUTTI, E.; GIRAFFA, L. Docência e cibercultura: mitos e possibilidades relacionados às tecnologias digitais. In: Didática e Prática de Ensino na relação com a Escola, EdUECE, 2015.

COSCARELLI, C. V. (Org.) Tecnologias para aprender. São Paulo: Parábola Editorial, 2016.

COURA-SOBRINHO, J. ; SANTOS, R. English Teachers no Brasil no século 21: O que a web e as novas tecnologias trazem para a aula de inglês? In: ARAÚJO, J. C.; DIEB, M.; LIMA, S. C. (Org.). Línguas na web: links entre ensino e aprendizagem. Ijuí, RS: Editora Unijuí, 2010. p.266 -291.

DEMO, P. Tecnofilia e Tecnofobia. Boletim Técnico. Senac: a R. Educ. Prof., Rio de Janeiro, v. 35, n.1, jan./abr. 2009

FREIRE, P. Pedagogia do oprimido. Rio de Janeiro: Paz e Terra, 1970.

FURTADO, P. Combater o futuro: um olhar sobre as representações "tecnofóbicas" de ciência e tecnologia na cinematografia moderna. E-topia: Revista Electrónica de Estudos sobre a Utopia, n. ${ }^{\circ}$ 10, 2009.

GALLARDO, B. C. Letramentos digitais e aprendizagem de língua inglesa nas redes sociais. In: RIBEIRO, A. L. et al. (Org.). Linguagem, tecnologia e educação. São Paulo: Peirópolis. 2010 . Cap. 23, p. 302-312.

GIBSON, W. Neuromancer. São Paulo: Aleph,1984 [2016].

GREEN, B. Subject-specific literacy and School learning: a focus on writing. Australia Journal of Education, 30(2), p. 156- 69, 1998.

HUNG, D. Engaged learning with emerging technologies. Springer, 2006

KRUMSVIK, R. J. Digital competence in Norwegian teacher education and schools. Högre utbildning. Vol. 1, jun. 2011, 39-51.

LAM, Y. Technophilia vs. Technophobia: A Preliminary Look at Why SecondLanguage Teachers Do or Do Not Use Technology in Their Classrooms. Canadian Modern Language Review, 2000, Vol.56(3), p.390-420.

LIMA, S. C.; ARAÚJO, J. C. Letramento digital em ambiente virtual de aprendizagem: descrição das práticas de leitura e escrita promovidas por propostas de atividades no curso de Letras/Inglês. In Araújo, J. C. et al. (Ed.). Línguas na web: links entre ensino e aprendizagem. Editora Unijuí, Ijuí, 2010, p. 243-266. 
MAIA, J. V. L. Ethos docente na narrativa tecnoautobiográfica: corporificação, ressiginificação e autorreflexão da imagem de si em récits de vie de professores. Tese (Doutorado em Linguística) UFC, Fortaleza, 2016.

McCAIN, T. \& JUKES, I. Windows on the future: Education in the age of technology.Thousand Oaks: Corwin Press, 2001.

NOGUEIRA, M.G. Letramento(s) digital(is) e jovens de periferia: o transitar por (multi)letramento(s) digital(is) durante o processo de produção de vídeos de vídeos de bolso. Dissertação (Mestrado) , UFPE, 2014.

PEREIRA, T. K. A importância do letramento digital nas aulas de língua inglesa. JORDÃO (org.) Letramentos e Multiletramentos no Ensino de Línguas e Literaturas. Revista X, vol.1, 2011

POSTMAN. N. Tecnopólio: a rendição da cultura à tecnologia. São Paulo: Nobel, 1994.

PRENSKY, M. Aprendizagem baseada em jogos digitais. Tradução Eric Yamagute; revisão técnica de Romero Tori e Denio Di Lascio. São Paulo: Editora Senac São Paulo, 2012.

PUENTEDURA, R.R. A brief introduction to TPACK and SAMR, 08/12/2011. Ruben Puentedura's weblog. Disponível em:

$<$ http:/www.hippasus.com/rrpweblog/archives/211/12/08/BriefIntroTPCKSAMR.pdf $>$. Acesso em : 10 ago. 2016.

RIBEIRO, A. E. Glossário Ceale. Termos de Alfabetização, Leitura e Escrita para educadores. UFMG. Disponível

em: $<$ http://www.ceale.fae.ufmg.br/app/webroot/glossarioceale/verbetes/tecnologiadigital>. Acesso em: 25 out. 2017.

RONIT, P. Technophilia: A New Model For Technology Adoption. UK Academy for Information Systems Conference Proceedings 2011. 41, 2011.

SELBER, S. A. Multiliteracies for a Digital Age. Carbondale: Southern Illinois University Press, 2004.

TAPSCOTT, D. A hora da geração digital. Tradução de Marcello Lino. Rio de Janeiro: Agir Negócios, 2010.

WHITE, D. S. Not "Natives" and "Immigrants" but "Visitors" and "Residents" TALL Blog. 2008. Disponível em: <http://tallblog.conted.ox.ac.uk/index.php/2008/07/23/notnatives-immigrants-but-visitors-residents/A>. Acesso em:10 ago. 2016.

WHITE, D. S.; LE CORNU, A. Visitors and Residents: A New Typology for Online Engagement. First Monday, 16(9). Disponível em:

$<$ http://firstmonday.org/arcticle/view/3171/3049>. Acesso em: 10 ago. 2016.

Recebido em 10 de setembro de 2020

Aceito em 13 de novembro de 2020 